\title{
Study on the Causes of the Decline of the Low Water Levels of Poyang Lake, China
}

\author{
Jian-Zhao Guan ${ }^{12}$, Lei Zhang ${ }^{12}$, Chun-Ming Fang ${ }^{12}$, and Jun Feng ${ }^{2}$ \\ ${ }^{1}$ State Key Laboratory of Simulation and Regulation of Water Cycle in River Basin, Beijing, 100038, China \\ ${ }^{2}$ China Institute of Water Resources and Hydropower Research, Beijing, 100038, China
}

\begin{abstract}
The drastic decline in the water level of Poyang Lake during the dry season has close connection with the water environment and lake ecology. The drastic decline has attracted considerable attention, and has led to intense scientific discussions regarding its cause. However, the importance of the different causes of the low water level decline has not been clearly illustrated. To improve the understanding of the reasons for the decline of low water levels in the Poyang Lake Waterway, this paper investigated the contributions of river channel erosion and sand mining to the water level decline. The results show that sand mining mainly occurred on the beaches of the Waterway, and had a relatively small effect on the change in the shape of the main river channel. It was found that the contribution of sand mining to the decline in the low water level was no more than $30 \%$, while the average contribution by natural erosion was about $85 \%$. This indicates that natural channel erosion of the Waterway has been significant, and plays a dominant role in the declining water levels of the Waterway.
\end{abstract}

\section{Introduction}

Poyang Lake (Fig. 1) is the largest freshwater lake in China, which plays an important flood storage role for the middle and lower reaches of the Yangtze River (Xu. et al., 2014; Fang et al., 2012; Shankman et al., 2006; Zhu and Zhang, 1997). Poyang Lake is also a vital component of the Yangtze River Basin's ecosystem, and provides habitats for rare and endangered species (Lai et al., 2014). Consequently, Poyang Lake is of major importance in the Yangtze River watershed management, development, and protection. However, the hydraulic characters of Poyang Lake have greatly changed in the past decades. Especially, the water level has dramatically decreased and the duration in days of extreme low water has significantly increased (Lai et al., 2014; Feng et al., 2012b; Liu et al., 2013). The low water levels have severely damaged ecological conservation and have had adverse effects on agricultural irrigation, water quality, and lake wetlands.

The reasons for the decline in the low water levels of Poyang Lake have been investigated from various perspectives. For instance, it was thought that the operation of the Three Gorges Dam (TGD) after 2003 is an important factor influencing the variation in the low water levels of Poyang Lake (Fang et al., 2012; Zhang et al., 2012). Another explanation, proposed by Liu et al. (2013), is that the water level decline is directly related to localized precipitation variations. A third explanation (Lai et al. 2014) is that the water level decline in Poyang Lake is largely due to the extensive sand mining.

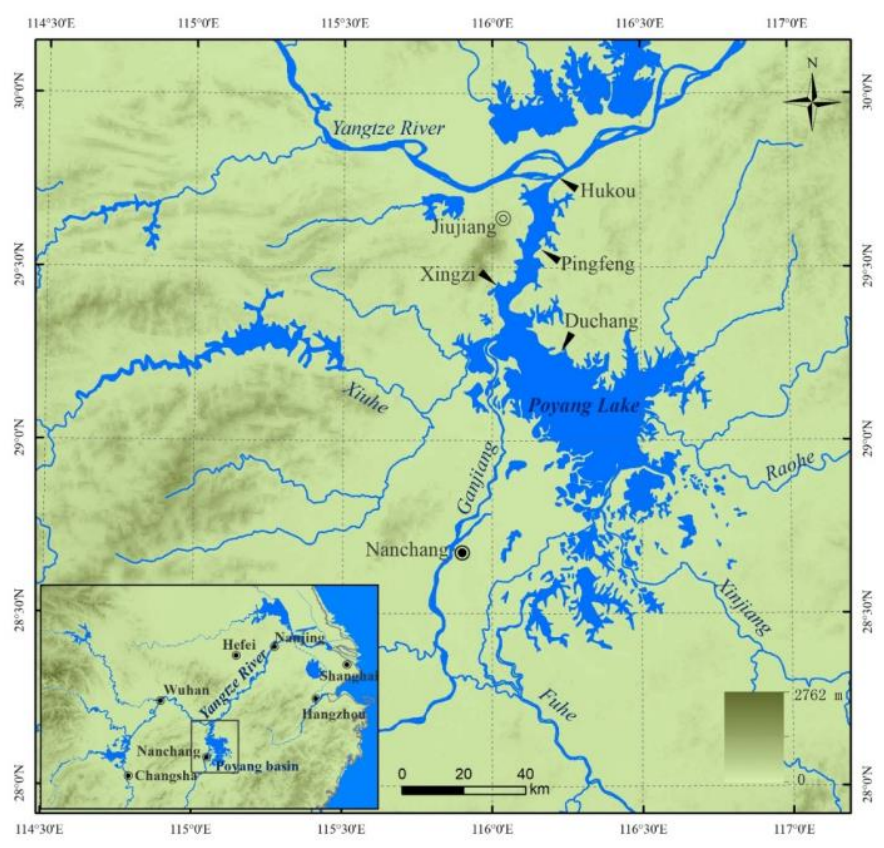

Fig. 1. Caption of the Figure 1. Below the figure.

In fact, the declining water level results from multiple factors, including localized precipitation variations (Liu et al., 2013), and changes in the blocking effect of the Yangtze River related to the TGD operations (Fang et al., 2012; Zhang et al., 2012). However, according to Lai et al. (2014), the findings of studies that identified local-ized precipitation variations and TGD operations as the primary factors causing decreasing lake water levels in recent years were questionable. These results did not consider changes of

\footnotetext{
Corresponding author: lei207b@163.com
} 
outflow channel in Poyang Lake and were therefore incomplete. Furthermore, the mean water level at Hukou station during dry winter season has remained almost constant (at about $8.5 \mathrm{~m}$ in 2001-2012) and earlier decades (1961-2000). This implies that the effect of the Yangtze River discharge change on the low water level can also be excluded (Lai et al., 2014). Therefore, in this paper, these factors were not considered further.

Because of increasing and widespread sand mining in Poyang Lake in recent years, the effect of sand mining on water level declines has received increased re-search attention (de Leeuw et al., 2010; Lai et al., 2014). However, it has not been determined which (if any) sand mining areas (located on beaches or in the main channel), have had a significant effect on the low water level changes in the Water-way. Further studies are needed. Therefore, this paper focuses on investigating the effects of sand mining, and natural channel erosion and deposition, on the low water level decline in Poyang Lake.

\section{Data collection}

The water levels at the Hukou gauging station which connects the Yangtze River and the Xingzi gauging station are very important; the Hukou station water levels represent the outflow water level of Poyang Lake, and the water levels at Xingzi station represent Poyang Lake water levels during the dry season. Daily hydrological data for these two stations (from 1950 to 2015) were obtained from the Hydrological Bureau of Jiangxi Province and from the Changjiang Water Resources Commission.

The calculation of the channel profile changes along the Waterway using a numerical model was based on channel profiles (scale 1:10000) measured by the Bureau of Hydrology (Changjiang Water Resources Commission) during 1998. To illustrate the effect of channel evolution and sand mining, the channel profiles for 2010 were extracted from a 1:10,000 relief map of the Waterway compiled by the Bureau of Hydrology in Jiangxi Province. The Bureau of Hydrology channel elevations are based on the National Vertical Datum 1985 of China; the Wusong Datum was used for water levels in this study. The topography data used in our study are the most detailed obtained thus far, and thus form an important foundation for the study.

\section{Methodology}

To calculate the water level variations in the Waterway caused by natural evolution, a 2-D flow-sediment mathematical model was used. This model was independently developed by the China Institute of Water Resources and Hydropower Research (Fang et al., 1997; 2003; China Institute of Water Resources and Hydropower Research, 2015). The model takes into account both bedload and suspended sediment transport. Because of its high accuracy, stability, and efficiency, this mod-el has been successfully used in studies of many major rivers in China and else-where, such as the Yangtze, Amur, and Lancang-Mekong Rivers.

The basic theory for the 2-D flow-sediment mathematical model is based on the non-equilibrium transport of non-uniform sediment (Fang et al., 1997; 2003). The curvilinear orthogonal partition mesh is used, and the governing equations are discretized by a finite difference method, and are solved by the Alternating Direction Implicit method

\subsection{Theoretical basis of the model}

Generally, a horizontal, 2-D mathematical model for flow motion involves the following equations of motion:

$$
\begin{aligned}
& \frac{\partial z}{\partial t}+\frac{\partial(\bar{u} h)}{\partial x}+\frac{\partial(\bar{v} h)}{\partial y}=0 \\
& \frac{\partial \bar{u}}{\partial t}+\bar{u} \frac{\partial \bar{u}}{\partial x}+\bar{v} \frac{\partial \bar{u}}{y}-\varepsilon\left(\frac{\partial^{2} \bar{u}}{\partial x^{2}}+\frac{\partial^{2} \bar{u}}{\partial y^{2}}\right)+g \frac{\partial z}{\partial x}=F_{x} \\
& \frac{\partial \bar{v}}{\partial t}+\bar{u} \frac{\partial \bar{v}}{\partial x}+\bar{v} \frac{\partial \bar{v}}{\partial y}-\varepsilon\left(\frac{\partial^{2} \bar{v}}{\partial x^{2}}+\frac{\partial^{2} \bar{v}}{\partial y^{2}}\right)+g \frac{\partial z}{\partial y}=F_{y}
\end{aligned}
$$

where $\mathrm{z}=$ water level; $\mathrm{h}=$ water depth; $\overline{\mathrm{u}}$ and $\overline{\mathrm{v}}$ are the depth-averaged velocity in the $\mathrm{x}$ and $\mathrm{y}$ directions; $\mathrm{g}$ is the acceleration of gravity; Fx and Fy are the flow resistance and other forces applied to the flow in the $\mathrm{x}$ and $\mathrm{y}$ directions; $\varepsilon$ is the momentum diffusion coefficient, which reflects not only turbulent diffusion, but also the non-uniformity of flow velocity in the direction of depth, and the influence of 3-D features (such as secondary flow). The value of $\varepsilon$ has a large amplitude of variation. To be numerically determined, the equations used in the model have to be rewritten in arbitrary orthogonal curvilinear coordinates:

$$
\begin{aligned}
\frac{\partial z}{\partial t}+\frac{1}{g_{\eta} g_{\xi}} \frac{\partial}{\partial \xi}\left(h u g_{\eta}\right)+\frac{1}{g_{\eta} g_{\xi}} \frac{\partial}{\partial \eta}\left(h v g_{\xi}\right)=0 \\
\frac{\partial u}{\partial t}+\frac{u}{g_{\xi}} \frac{\partial u}{\partial \xi}+\frac{v}{g_{\eta}} \frac{\partial u}{\partial \eta}+\frac{u v}{g_{\xi} g_{\eta}} \frac{\partial g_{\xi}}{\partial \eta}-\frac{v^{2}}{g_{\xi} g_{\eta}} \frac{\partial g_{\eta}}{\partial \xi}+\frac{g}{g_{\xi}} \frac{\partial z}{\partial \xi}=\varepsilon\left(\frac{1}{g_{\xi}} \frac{\partial A}{\partial \xi}-\frac{1}{g_{\eta}} \frac{\partial B}{\partial \eta}\right)+F_{\xi} \\
\frac{\partial v}{\partial t}+\frac{u}{g_{\xi}} \frac{\partial v}{\partial \xi}+\frac{v}{g_{\eta}} \frac{\partial v}{\partial \eta}+\frac{u v}{g_{\xi} g_{\eta}} \frac{\partial g_{\eta}}{\partial \xi}-\frac{u^{2}}{g_{\xi} g_{\eta}} \frac{\partial g_{\xi}}{\partial \eta}+\frac{g}{g_{\eta}} \frac{\partial z}{\partial \eta}=\varepsilon\left(\frac{1}{g_{\eta}} \frac{\partial A}{\partial \eta}+\frac{1}{g_{\xi}} \frac{\partial B}{\partial \xi}\right)+F_{\eta} \\
A=\left[\frac{\partial}{\partial \xi}\left(u g_{\eta}\right)+\frac{\partial}{\partial \eta}\left(v g_{\xi}\right)\right] / g_{\eta} g_{\xi} \\
B=\left[\frac{\partial}{\partial \xi}\left(v g_{\eta}\right)-\frac{\partial}{\partial \eta}\left(u g_{\xi}\right)\right] / g_{\eta} g_{\xi} \\
g_{\xi}=\sqrt{x_{\xi}^{2}+y_{\xi}^{2}}, \quad g_{\eta}=\sqrt{x_{\eta}^{2}+y_{\eta}^{2}}, \\
u=g_{\xi} \frac{\partial \xi}{\partial t}, \quad v=g_{\eta} \frac{\partial \eta}{\partial t}
\end{aligned}
$$

where $g_{\xi}$ and $g_{\eta}$ are the Lame coefficients, and $F_{\xi}$ and $F_{\eta}$ are the flow resistance and other forces applied to flow in the $\xi$ and $\eta$ directions, respectively.

With respect to non-uniform sediment, particles of all sizes can satisfy the non-equilibrium suspended load discharge equation when sediment concentration is not too high. The commonly used horizontal, 2-D, non- 
equilibrium suspended load discharge equation, is as follows:

$$
\frac{\partial S_{l}}{\partial t}+\frac{\partial\left(h u S_{l}\right)}{\partial x}+\frac{\partial\left(h v S_{l}\right)}{\partial y}-\frac{\partial}{\partial x}\left(\varepsilon h \frac{\partial S}{\partial x}\right)-\frac{\partial}{\partial y}\left(\varepsilon h \frac{\partial S}{\partial y}\right)=-\omega_{l} \alpha_{l}\left(S-S_{l}^{*}\right)(3)
$$

In the orthogonal curvilinear coordinate system, the equation is written as:

$$
\begin{aligned}
& \frac{\partial\left(h u S_{l} g_{\eta}\right)}{\partial \xi}+\frac{\partial\left(h v S_{l} g_{\xi}\right)}{\partial \eta}-\varepsilon h\left[\frac{\partial}{\partial \xi}\left(\frac{g_{\eta}}{g_{\xi}} \frac{\partial S_{l}}{\partial \xi}\right)+\frac{\partial}{\partial \eta}\left(\frac{g_{\xi}}{g_{\eta}} \frac{\partial S_{l}}{\partial \eta}\right)\right](4) \\
& =-\omega_{l} \cdot \alpha_{l}\left(S_{l}-S_{l}^{*}\right) \cdot g_{\eta} g_{\xi}
\end{aligned}
$$

where 1 represents the $1_{\text {th }}$ non-uniform sediment group; $\omega_{1}$ is the settling velocity of the lth group; $\alpha_{1}$ is the saturation recovery coefficient; and $\mathrm{S}_{1} *$ is the sediment carrying capability of the 1th group. The 2-D, nonequilibrium suspended load discharge equation is a convection diffusion equation, is relatively simple, and can be solved by the Alternating Direction Implicit method. The equation is discretized into a conservation form; the upwind discrete scheme is used for the convection term and the central difference scheme is used for the diffusion term.

The following bed load discharge equations are used in the model:

$$
\begin{gathered}
G_{b}=0.95 D^{0.5}\left(U-U_{c}\right)\left(\frac{U}{U_{c}}\right)^{2}\left(\frac{D}{h}\right)^{\frac{1}{4}} \\
U_{c}=1.34\left(\frac{h}{D}\right)^{0.14}\left(\frac{\gamma_{s}-\gamma}{\gamma}\right)^{0.5}
\end{gathered}
$$

where $D$ is the particle size of the bed sediment; $\gamma_{\mathrm{s}}$ is the unit weight of the bed sediment; and $\gamma$ is the unit weight of water.

The non-equilibrium suspended load discharge may cause changes in riverbed erosion and deposition, and changes in the composition of bed sediment. Using the sediment conservation law, the riverbed deformation caused by non-equilibrium suspended load discharge is written as:

$$
\gamma_{s} \frac{\partial Z_{b}}{\partial t}=\sum_{l} \omega_{l} \alpha_{l}\left(S_{l}-S_{l}^{*}\right)+\sum_{l}\left(B_{l}^{1}-B_{l}^{0}\right)
$$

where $Z_{b}$ is the riverbed elevation, and $B_{1}{ }^{0}$ and $B_{1}{ }^{1}$ are the bedload input and output.

\subsection{Calibration and validation}

Before using this model to simulate the evolution variations in the Waterway, calibration and verification needs to be done. Hydrological data from 1998 was used to calibrate the model, and hydrological data from 1999 to 2004 was used to verify the model based on the measured topography during 1998 . The calculated water levels for the Xingzi and Pingfeng (location shown in Fig. 1) gauging stations were compared with the measured data, and a very close fit was obtained (Fig. 2). Based on the verification results for the water levels, the erosion and deposition variations for Poyang Lake were calculated using the series data from 1998-2010. The results show that the volume of erosion in the Waterway from 1998 to 2010 was about $1.00 \times 108 \mathrm{t}$, which is in agreement with the estimated erosion volume $1.005 \times 108$ t. Therefore, the present model can be used to calculate the evolution variation of the Waterway.

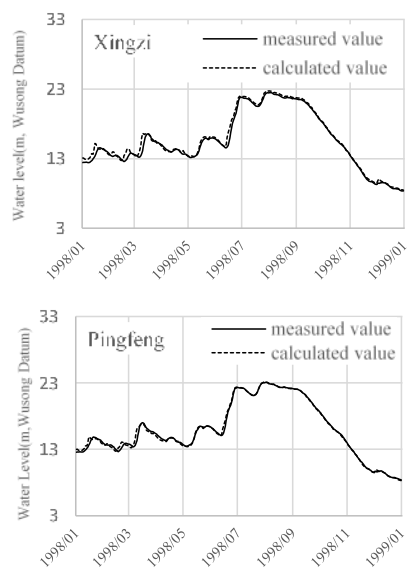

(a)

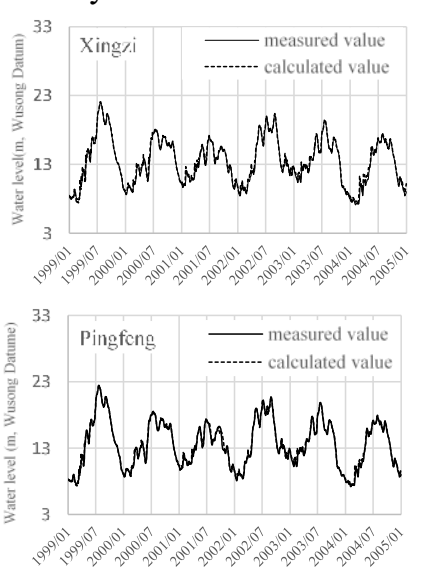

(b)
Fig. 2. Calibration (a) and verification (b) of the 2-D model water levels

\section{Results}

In an attempt to clarify the relative contributions of sand mining and natural river erosion to the change in channel shape, we used a 2-D flow-sediment mathematical model to calculate the scour and silting evolution of the Waterway. The initial topography used in the model was the measured topography for 1998. The flow discharge and sediment load at the entrance of the Waterway were calculated using a 1-D river network model of Poyang Lake (Institute of Water Resources and Hydropower Research, 2015). For the water depth of the outletsection (set at the Hukou gauging station), measured data from 1998-2010 was used. The results are shown in Fig. 3(B). Cross-sections 1-9 illustrate the change in the channel shape. It shows that:

(1) From 1998 to 2010 bed elevation variation in the Waterway is characterized by slight deposition along the banks and scouring along the main channel, and is evident in both the measured and calculated topography; (2) Irregular changes in the measured topography (Fig. 6A) at cross-sections HQ5, 7, and 9, were not observed in the calculated topography (Fig. 6B). It seems reasonable to infer that the irregular changes observed in Fig. 6A were largely the result of sand mining.

(3) The measured thickness of scouring in the main channel from 1998-2010 was slightly greater than the calculated result; this may be a result of the greater accuracy of the measured topographical data. The differences could also have been caused by sand mining in the main channel increasing the measured thickness of scouring. 


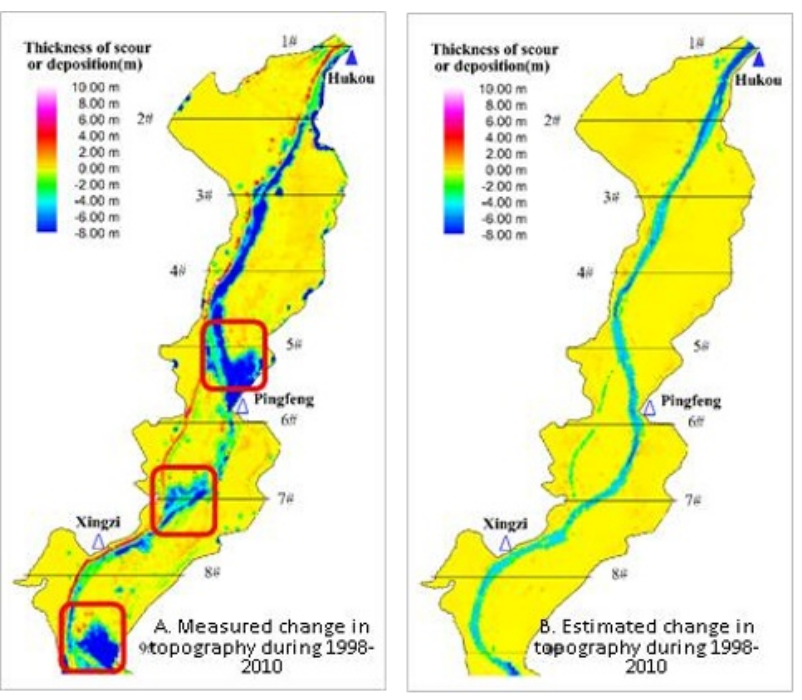

Fig. 3. Comparison between measured and simulated changes in the Waterway's topography

To further illustrate the effects of sand mining in these sections, the shape changes for typical crosssections (HQ 2-9) are presented in Fig. 4. The bed elevations for cross-sections HQ 5, 7, and 9 were seriously disturbed by sand mining. Based on the measured data, the total sediment load at cross-sections HQ 5, 7, and 9 decreased by nearly 160 million $\mathrm{m} 3$ from 1998-2010. The sediment load decreased by about 60 million $\mathrm{m} 3$ at HQ 5, 30 million $\mathrm{m} 3$ at HQ 7, and 70 million $\mathrm{m} 3$ at HQ 9. It can be seen from Fig. 4 that sand mining created clear excavated areas on the beaches shown in the cross-sections. However, the measured topography of the main channel in HQ 5, 7, and 9 was similar to the simulated result, which only considered the effect of natural scouring and deposition. This implies that sand mining primarily occurred on the beaches. At cross-sections HQ 2, 3, 4, 6, and 8 (representative crosssections of the main channel) sand mining has some influence on the shape change in these sections. However, it is clear that the main channel was principally deepened by scouring. Thus, it can be generalized that, although sand mining affects the scouring thickness of the main channel to some extent, the effect of natural channel scouring is the dominant process. Most of the water flow in the Waterway's main channel occurs during the dry season. Therefore, it can be inferred that the low water level decline in the Waterway is mainly the result of natural channel scouring, rather than sand mining.

To further estimate the contributions of natural channel scouring and sand mining to the low water level decline of the Waterway, the contributions of sand mining and natural scouring for different cross-sections were calculated, and are shown in Table 1. It can be seen that sand mining is widespread. However, its effect on the low water level decline is very limited; the greatest contribution is about $26 \%$ in cross-section 7 . The contribution of natural scouring on the low water level decline is about $74 \%-100 \%$, indicating that the effect of natural scouring is dominant.
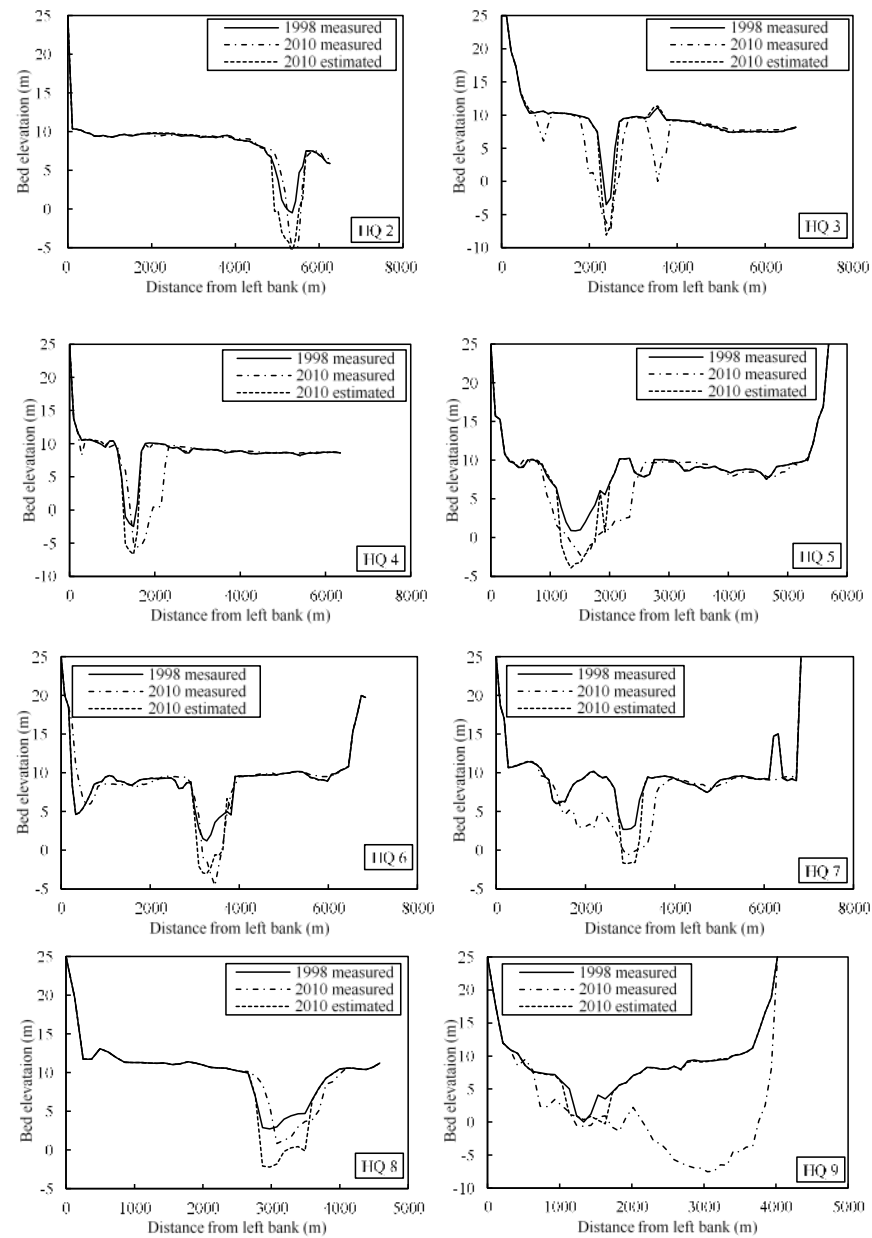

Fig. 4. Changes in the shape of typical cross-sections of the Waterway's main channel

Table. 1. Comparison of the effects of natural scouring and sand mining on low water levels at selected typical crosssections

\begin{tabular}{|c|c|c|c|c|c|}
\hline \multirow{2}{*}{$\begin{array}{c}\text { Cross- } \\
\text { section } \\
\text { No. }\end{array}$} & \multicolumn{2}{|c|}{ low water level change(m) } & \multicolumn{2}{c|}{ Contribution } \\
\cline { 2 - 6 } & Total & scouring & $\begin{array}{c}\text { Sand } \\
\text { mining }\end{array}$ & scouring & $\begin{array}{c}\text { sand } \\
\text { mining }\end{array}$ \\
\hline \multirow{2}{*}{4} & $-0.18 \sim$ & $-0.18 \sim$ & $0 \sim$ & $89 \% \sim$ & $0 \% \sim$ \\
& -0.45 & 0.40 & -0.05 & $100 \%$ & $11 \%$ \\
\hline \multirow{2}{*}{$5 \sim 6$} & $-0.60 \sim$ & $-0.55 \sim$ & $-0.05 \sim$ & $78 \% \sim$ & $8 \% \sim$ \\
& -0.90 & -0.70 & -0.20 & $92 \%$ & $22 \%$ \\
\hline \multirow{2}{*}{7} & $-1.00 \sim$ & $-0.85 \sim$ & $-0.10 \sim$ & $74 \% \sim$ & $10 \% \sim$ \\
& -1.15 & -0.90 & -0.25 & $90 \%$ & $26 \%$ \\
\hline \multirow{2}{*}{8} & -1.20 & $-0.90 \sim$ & $-0.15 \sim$ & $75 \% \sim$ & $12 \% \sim$ \\
& $-1.15 \sim$ & $-1.00 \sim$ & $-0.05 \sim$ & $87 \% \sim$ & $4 \% \sim$ \\
\multirow{2}{*}{9} & -1.20 & -1.15 & 0.15 & $96 \%$ & $13 \%$ \\
\hline
\end{tabular}

\section{Conclusions}

This paper has demonstrated that the water level decline in Poyang Lake during the dry season is due to natural scouring and sand mining that began in 2004. The contributions of these two factors to water level declines were estimated using numerical modeling. The following conclusions were drawn: 
(1) Sand mining has some effect on Poyang Lake water levels. However, sand mining is mainly located on Waterway beaches, and has had little effect on the evolution of changes in the main channel. Most of the water flow in the main channel occurs during the dry season, away from the beach areas, and thus it can be inferred that the effect of sand mining on the low water level decline of the Waterway is limited.

(2) To investigate this inference further, the contributions of natural erosion and sand mining to the low water level decline were analyzed. It was found that the greatest contribution of sand mining was no more than $30 \%$, and that the average contribution of natural erosion was about $85 \%$. Therefore, it was concluded that natural channel erosion plays the dominant role in the low water level decline of Poyang Lake.

\section{Acknowledgments}

Financial support from the National Key R\&D Program of China (Nos. 2017YFC0405304 and 2016YFC0402304), the IWHR Research \& Development Support Program (Nos. SE0145B702017 and SE0145B792017), and the National Natural Science Foundation of China (NSFC, Grant No. 51609264) is gratefully acknowledged.

\section{References}

1. China Institute of Water Resources and Hydropower Research, 2015. Study on the variation of the low water level of Poyang Lake (Beijing, China). (in Chinese)

2. De Leeuw, J., Shankman, D., Wu, G., de Boer, W.F., Burnham, J., He, Q., Yesou, H., Xiao, J., 2010. Strategic assessment of the magnitude and impacts of sand mining in Poyang Lake, China. Reg. Environ. Change. 10, 95-102.

3. Fang, C.M., Cao, W.H., Mao, J.X., Li, H.J., 2012. Relationship between Poyang Lake and Yangtze River and Influence of Three Gorges Reservoir. Journal of Hydraulic Engineering, 43(2), 175181.(in Chinese)

4. Feng, L., Hu, C., Chen, X., Cai, X., Tian, L., Gan, W., 2012b. Assessment of inundation changes of Poyang Lake using MODIS observations between 2000 and 2010. Remote Sens. Environ. 121, 80-92.

5. Lai, J., Shankman, D., Huber, C., Yesou, H., Huang, Q., Jiang, J., 2014. Sand mining and increasing Poyang Lake's discharge ability: A reassessment of causes for lake decline in China. J Hydrol, 519, 1698-1706.

6. Li S.Q., Min Q., Tan G.L., et al., 2008. Cause analysis of low water characteristics of Poyang Lake in 2006. Journal of China Hydrology, 28(6), 73-76. (in Chinese)

7. Liu, Y., Wu, G., Zhao, X., 2013. Recent declines in China's largest freshwater lake: trend or regime shift?. Environ. Res. Lett. 8, 014010.
8. Shankman, D., Keim, B. D., Song, J., 2006. Flood frequency in China's Poyang Lake region: trends and teleconnections . International Journal of Climatology, 26(9),1255-1266.

9. Wang, Y., Lai, X., Jiang, J., Huang, Q., 2011. Effect of the Three Gorge Reservoir on the water regime of the Lake Poyang wetlands during typical waterregulation period. J. Lake Sci. 23, 191-195 (in Chinese).

10. Xu Z.M., Hu W.Z., You Z.Q., 2014. Analysis of low flow situation of Poyang Lake area after operation of Three Gorges Reservoir and its causes. Yangtze River, 7, 18-22. (in Chinese)

11. Zhang, Q., Li, L., Wang, Y.G., Werner, A.D., Xin, P., Jiang, T., Barry, D.A., 2012. Has the ThreeGorges Dam made the Poyang Lake wetlands wetter and drier?. Geophys. Res. Lett. 39, L20402.

12. Zhu H., Zhang, B., 1997. Poyang Lake. Press of University of Science and Technology of China, Hefei. (in Chinese). 